\title{
Determinants of Blood Pressure among Youth in Ajman, UAE
}

\author{
Sreedharan J11, Mathew E², Muttappallymyalil J33, Sharbatii S A ${ }^{4}$, Shaikh R B5 ${ }^{5}$, Basha S A ${ }^{6}$
}

${ }^{1}$ Assistant Director, Research Division, Gulf Medical University, Ajman, UAE

2 Professor, Department of Community Medicine, Gulf Medical University, Ajman, UAE

${ }^{3}$ Research Associate, Research Division, Gulf Medical University, Ajman, UAE

${ }^{4}$ Professor and Head, Department of Community Medicine, Gulf Medical University, Ajman, UAE

${ }^{5}$ Assistant Professor, Department of Community Medicine, Gulf Medical University, Ajman, UAE

${ }^{6}$ Specialist and Head, Department of Internal Medicine, Gulf Medical College Hospital and Research Centre,

Ajman, UAE

\section{Original Article}

\section{Corresponding Author:}

Dr. Jayadevan Sreedharan, Assistant Director, Research Division, Gulf Medical University, Ajman, UAE.

Email: drjayadevans@gmail.com

\section{Abstract}

\section{Background \\ Youth is a vulnerable group for developing almost all life- style related diseases. The present cross-sectional study was conducted to assess the determinants of blood pressure among entry year students in a medical university in Ajman, United Arab Emirates.}

\section{Materials and Methods}

One hundred and ten students from Gulf Medical University, Ajman, UAE participated in the study. A pretested structured questionnaire was used for data collection. Predictive Analytic Software 17 was used for data analysis. Chi-square test, Univariate and multivariate logistic regression were used.

\section{Results}

Variables such as tobacco use, duration of sleep, Body Mass Index and gender were considered to assess the association with blood pressure. The mean age of the students was 19 years with a SD of 1.9 years. The mean systolic and diastolic blood pressure was 113.5 (SD 12.0) and 73.7 (SD 11.2) respectively with mean $\mathrm{BMI}$ of 24.9 (SD 5.7). A statistically significant association was observed between gender and blood pressure $(p<0.05)$. The crude Odds Ratio (OR) observed for sleep duration and blood pressure was found statistically significant $(p<0.05)$, but the adjusted OR was not statistically significant. Of the participants who sleep for more than 6 hours, majority (70\%) have normal blood pressure. Nearly half of the participants who slept for less than 6 hours have pre-hypertension and/ or hypertension. There was statistically significant $(p<0.005)$ association between Body Mass Index (BMI) and blood pressure (BP). The mean BMI among those with normal BP was 23.25 $\mathrm{kg} / \mathrm{m}^{2}$ with a SD of 4.6 and those with pre-hypertension and/ or hypertension was $27.6 \mathrm{~kg} / \mathrm{m}^{2}$ with a SD of 6.5 .

\section{Conclusion}

Gender and BMI are the significant factors associated with Blood pressure. The findings may be used to create strategies to impart awareness of the dangers of increased blood pressure among obese and non obese students.

\section{Key Words}

Body Mass Index, Blood Pressure, UAE

\section{Background}

Hypertension is a major public health problem of concern across the world because of its association with increased risk of cardiovascular diseases. Youth (15 to 24 years) is an 
important period of growth and maturation, and most of the changes that occur during this period are continued into adulthood $^{1}$.

Essential hypertension may have its origins in early life and its co-morbidities are certainly a major burden on resources, and they reduce the productivity of those affected with hypertension ${ }^{2}$. Prospective studies have established increased left ventricular mass and peripheral resistance, with high blood pressure in childhood ${ }^{3-4}$. Raised BP in childhood has been recognized as one of the most important predictors of adult hypertension. This has generated an interest among researchers to investigate the pattern of blood pressure and its determinants in childhood and adolescence ${ }^{5-6}$.

Several studies have shown that the level and pattern of blood pressure among children and adolescents vary from population to population ${ }^{7}$. Growth patterns, age and gender have strong influence on blood pressure ${ }^{7}$. It has been estimated that by 2010, 1.2 billion people will suffer from hypertension worldwide 8 . The prevalence of hypertension averages $26 \%$ and it affects approximately 125 million individuals in the Eastern Mediterranean Region ${ }^{9}$.

The United Arab Emirates (UAE) is in a period of transition. As late as the 1960s nomadic Bedouin Arabs were the population of UAE. The discovery of oil in 1970s has made a dramatic change in the demographic profile with expatriates constituting more than $80 \%$ of the population and in the lifestyle of its people. Now the UAE is a modern, wealthy society, heavily influenced by Western living patterns, including a sedentary lifestyle with high Cardiovascular Diseases (CVD) risk profiles ${ }^{10}$. Indeed, CVDs are known to be the leading cause of morbidity and mortality in the UAE among both the nationals and expatriates $^{11}$. Of particular concern is the prevalence of obesity, which reaches approximately $24 \%$ among medical students ${ }^{12}$ with reported high stress levels (65\%), unhealthy diets (50\%) and low levels of physical activity (77\%) which is perhaps attributable to cultural and climatic restrictions ${ }^{13}$. Smoking has increased among men ${ }^{14-16}$. Hypertension is also common with a reported prevalence of $19-25 \%{ }^{17}, 15.3 \%$ in urban and $10.6 \%$ rural population ${ }^{18}$. The $15-24$ years age is an important developmental stage in the life span of individuals as it is a transition period to adulthood.

In Ajman, there is a lack of data about determinants of hypertension among youth. This information is important in planning life style modifications. Therefore, the present study was an attempt to assess the determinants of blood pressure such as gender, academic programme in which they were enrolled, tobacco use, number of meals and BMI among students in a medical university in Ajman, United Arab Emirates.

\section{Materials and Methods}

This study was conducted among entry year students in a Medical University of Ajman, United Arab Emirates. Students enrolled in Medicine, Dental Medicine, and Allied (Pharmacy and Physical Therapy) academic programmes during the year 2009-2010 were included in the study. Among 160 entry level students, 110 students participated in the study with a response rate of $69 \%$. Verbal consent was obtained from the participants before the study. A selfadministered questionnaire was distributed among them to obtain information on socio-demographic characteristics, physical activity, habits, diet history, daily sleeping habits and family history of metabolic disorders. Their height, weight and blood pressure were recorded. The height was measured on a vertical scale with heels, buttocks, and occiput against the wall and head in Frankfurt plane, to the nearest $0.5 \mathrm{~cm}$. Weight was measured on a weighing scale with standard minimum clothing to the nearest $0.5 \mathrm{~kg}$. Body Mass Index was calculated using the formula - weight (in kg.) divided by height ${ }^{2}$ (in mtr.). Categorisation of BMI was done based on the World Health Organisation (WHO) criteria into three categories: normal (BMI $=18.5-24.9 \mathrm{~kg} \mathrm{~m}$ $\left.{ }^{2}\right)$, overweight $\left(\mathrm{BMI}=25-29.9 \mathrm{~kg} \mathrm{~m}^{-2}\right)$ and obese $(\mathrm{BMI} \geq 30$ $\mathrm{kg} \mathrm{\textrm {m } ^ { - 2 }}$ ). Blood pressure was measured by same team and interpreted as per the blood pressure guidelines, issued in 2003 by the National Heart, Lung, and Blood Institute as shown below ${ }^{19}$.

\begin{tabular}{|l|l|l|}
\hline \multicolumn{1}{|c|}{ Category } & $\begin{array}{l}\text { Systolic Blood } \\
\text { pressure } \\
\text { (mmHg) }\end{array}$ & $\begin{array}{l}\text { Diastolic Blood } \\
\text { pressure } \\
\text { (mmHg) }\end{array}$ \\
\hline $\begin{array}{l}\text { Normal } \\
\text { Less than 120 }\end{array}$ & Less than 80 \\
\hline $\begin{array}{l}\text { Hypertension - Stage1 } \\
\text { Hypertension - Stage2 }\end{array}$ & $120-139$ & $80-89$ \\
\hline
\end{tabular}

Descriptive statistics such as means and standard deviation were used to summarize the quantitative variables. Proportions and percentages were used to summarize categorical variables. Chi-square test examined the relationship between biological variables such as overweight, obesity and non-biological factors. A p-value $\leq$ 0.05 was considered as statistically significant.

\section{Results}

Table 1 shows the distribution of blood pressure according to different variables. With regard to gender, $29.8 \%$ females and $61.5 \%$ males were either pre-hypertensive or hypertensive. There was a statistically significant association between gender and blood pressure $(p<0.05)$. The association between duration of sleep and blood pressure was found to be statistically significant $(p<0.05)$. $70 \%$ of those who slept for 6 hours or more and $50 \%$ of those who slept for less than 6 hours had normal blood pressure. There was no statistically significant difference in the blood pressure of students from the different academic programmes. Tobacco use and number of meals consumed also did not show statistically significant association with blood pressure. However, there were only eight tobacco users of whom five had pre-hypertension or hypertension while among the non users, three had pre-hypertension or hypertension. Among the participants with $\mathrm{BMI}>30,66.7 \%$ 
had pre-hypertension or hypertension whereas among those with $\mathrm{BMI}<30$, only $31.5 \%$ were pre-hypertensive or hypertensive. The association between BMI and blood pressure was statistically significant $(p<0.005)$. The mean BMI among those with normal BP was 23.25 with a SD of 4.6, while among those with pre-hypertension or hypertension was 27.6 with a SD of 6.5 .

Table-1: Distribution of Blood Pressure according to different variables

\begin{tabular}{|c|c|c|c|c|c|c|c|}
\hline \multirow{3}{*}{ Variables } & \multirow{3}{*}{ Group } & \multicolumn{4}{|c|}{ Blood Pressure } & \multirow{3}{*}{ Total } & \multirow{3}{*}{$\begin{array}{l}\text { Signific } \\
\text { ance }\end{array}$} \\
\hline & & \multicolumn{2}{|c|}{ Normal } & \multicolumn{2}{|c|}{$\begin{array}{c}\text { Pre/Hyper } \\
\text { tension }\end{array}$} & & \\
\hline & & No. & $\%$ & No. & $\%$ & & \\
\hline \multirow[t]{2}{*}{ Gender } & Female & 59 & 70.2 & 25 & 29.8 & 84 & \multirow{2}{*}{$<0.05$} \\
\hline & Male & 10 & 38.5 & 16 & 61.5 & 26 & \\
\hline \multirow[t]{3}{*}{ Programme } & MBBS & 28 & 54.9 & 23 & 45.1 & 51 & \multirow[t]{3}{*}{ NS } \\
\hline & Allied & 24 & 77.4 & 7 & 22.6 & 31 & \\
\hline & DMD & 17 & 60.7 & 11 & 39.3 & 28 & \\
\hline \multirow{2}{*}{$\begin{array}{l}\text { Sleep } \\
\text { duration }\end{array}$} & $<6 \mathrm{hrs}$ & 20 & 50.0 & 20 & 50.0 & 40 & \multirow[t]{2}{*}{$<0.05$} \\
\hline & $\geq 6 \mathrm{hrs}$ & 49 & 70.0 & 21 & 30.0 & 70 & \\
\hline \multirow[t]{2}{*}{ Tobacco use } & Yes & 3 & 37.5 & 5 & 62.5 & 8 & \multirow[t]{2}{*}{ NS } \\
\hline & No & 66 & 64.7 & 36 & 35.3 & 102 & \\
\hline \multirow{2}{*}{$\begin{array}{l}\text { Number of } \\
\text { meals }\end{array}$} & 2 meals & 35 & 61.4 & 22 & 38.6 & 57 & \multirow[t]{2}{*}{ NS } \\
\hline & $\begin{array}{l}>2 \\
\text { meals }\end{array}$ & 34 & 64.2 & 19 & 35.8 & 53 & \\
\hline \multirow[t]{2}{*}{ BMI } & $\leq 30$ & 63 & 68.5 & 29 & 31.5 & 92 & \multirow[t]{2}{*}{$<0.005$} \\
\hline & $>30$ & 6 & 33.3 & 12 & 66.7 & 18 & \\
\hline
\end{tabular}

Table 2: Multivariate logistic regression analysis of factors associated with hypertension

\begin{tabular}{|l|l|l|l|l|l|}
\hline Factors & Group & Number & $\begin{array}{c}\text { Adjusted } \\
\text { Odds Ratio }\end{array}$ & 95\% Cl & P value \\
\hline BMI & & 110 & 1.14 & $1.05-1.23$ & $<\mathbf{0 . 0 0 2}$ \\
Gender & Female & 84 & 1 & -- & \\
& Male & 26 & 3.30 & $1.24-8.78$ & $<0.02$ \\
\hline $\begin{array}{l}\text { Sleep } \\
\text { duration }\end{array}$ & $>6$ hrs & 70 & 1 & -- & \\
\hline
\end{tabular}

For further analysis, the significant variables from the Chisquare test such as BMI, gender, and sleep duration were included. Logistic regression analysis was performed to find the crude and adjusted odds ratio (OR). BMI was taken as a continuous variable, and gender and sleep duration as categorical variables. The adjusted odds ratio for BMI was
1.14 , which was statistically significant. There is $14 \%$ increased chance for getting pre-hypertension or hypertension for a unit increase in BMI. Among the male gender, the adjusted odds ratio was 3.3, which was statistically significant. The chance of getting prehypertension and/ or hypertension for male gender was 3.3 times more compared to female gender. The crude odds ratio for sleep duration was 2.3 and was statistically significant but when adjusted with other factors it was not statistically significant. Table 2 shows the details of logistic regression analysis.

\section{Discussion}

Studies have reported sex differences in BP with males having higher BP than females during adolescent and early adulthood $^{20-21}$. Smith and Rinderknecht report that older boys have significantly higher BP than girls ${ }^{22}$. Kusuma et al and Schall observed that men possess higher BP levels than females ${ }^{23-24}$. The present study also supports the observation made by other authors in this respect. Gender difference in the pathogenic mechanisms in essential hypertension is available in the literature. The high prevalence of hypertension in younger men compared to women is explained on the basis of the lack of endogenous estrogen. Evidence suggests that estrogen may modulate vascular endothelial function, causing vasodilatation. This may be one reason for women having lower blood pressure compared to men ${ }^{25}$.

Previous studies demonstrated that hypertension increased significantly as BMI increased ${ }^{26-29}$. Srinivasan et al reported that $\mathrm{BMI}$ or central adiposity are the key determinants of high blood pressure which appear at an early age. The study also emphasizes the role of weight reduction in the prevention of hypertension $^{30}$. A study conducted among adolescents observed that $\mathrm{BMI}$ is associated with arterial hypertension $^{31}$. Reich et al. report that BMI is a strong predictor of hypertension than waist-hip ratio ${ }^{32}$. Study by Berenson et al. observed high BMI as one of the strongest risk factors for hypertension ${ }^{33}$. The present study also supports the observation made by other authors with regard to BMI. Currently, there is little direct evidence to explain the role of obesity in hypertension. Davy and Hall point out that high BP in obese humans may be due to higher level of adiposity ${ }^{34}$. BMI measures obesity and is associated with increased arterial stiffness and various hemodynamic changes that may contribute to hypertension $^{35-38}$.

Jervase et al. reported differences in BP between males and females, with males having higher systolic and diastolic BP than the females. The study also observed that gender and BMI were the significant determinants of hypertension among university students ${ }^{39}$. A study by Chirinos et al. reported that increasing BMI was associated with a significantly increased risk of hypertension and the Odds Ratio for hypertension, for every 5-unit increase in BMI, was 1.58. The study concluded that younger persons with hypertension were more likely to be obese compared with 
older persons with hypertension ${ }^{40}$. In the present study, OR for hypertension was 1.14 , which revealed that for every one unit increase in $\mathrm{BMI}$, the chance of hypertension is $14 \%$ more, which is similar to the findings of Chirinos et al.

In the present study, when studying the association between BMI and hypertension, physical activity may be a confounding factor, but physical activity was not taken in to account in this study. There was no association between blood pressure and other risk factors like tobacco use and sleep duration. With regard to sleep duration, before adjusting to other confounding variables, the crude odds ratio of 2.33 was observed, but the adjusted OR observed was not statistically significant. Gangwisch et al $^{41}$ reported that less sleep duration significantly increased the risk of hypertension in subjects 32 to 59 years of age. Gottlieb et $\mathrm{al}^{42}$ observed that sleep duration per night is associated with an increased risk of hypertension, which is not supported by the findings of the present study. This result may not be representative of all university students as the present study involves only one university and the small sample size. This investigation highlights the need for a nationwide study among youth.

\section{Conclusion}

The results of this study provide an insight into the understanding of the association between gender, BMI and blood pressure among our entry level students. The results may be used to develop messages to raise awareness about the dangers of high blood pressure and its determinants among students. This result may not be representative of all university students as the present study involves only one university. This investigation highlights the need for a nationwide study among youth.

\section{Acknowledgement}

Authors would like to express their gratitude to Rehna Sameer, Jancy Joshi and Shanavas Kunjahmmed for the help rendered during data entry, coding and analysis.

\section{Conflict of Interests}

The authors do not have any conflict of interest arising from the study.

\section{References}

1. Health needs of adolescents. Report of a WHO Expert Committee. Geneva, World Health Organization 1977 (WHO Technical Report Series, No. 609). Available from URL: whqlibdoc.who.int/trs/WHO TRS 609.pdf

2.Grover SA, Ho V, Lavoie F, Coupal L, Zowall H, Pilote L. The importance of indirect costs in primary cardiovascular disease prevention: can we save lives and money with statins? Arch Intern Med 2003; 163(3): 333-9.

3.Lever AF, Harrap SB. Essential hypertension: a disorder of growth with origins in childhood? J Hypertens 1992; 10(2):
101-20.

4.Daniels SR, Loggie JM, Khoury P, Kimball TR. Left ventricular geometry and severe left ventricular hypertrophy in children and adolescents with essential hypertension. Circulation 1998; 97(19): 1907-11.

5.Chadha SL, Vasan RS, Sarma PS, Shekhawat S, Tandon R, Gopinath N. Age- and height-specific reference limits of blood pressure of Indian children. Natl Med J India 1999; 12(4):150-6.

6.Lawlor DA, Smith GD. Early life determinants of adult blood pressure. CurrOpinNephrolHypertens 2005; 14(3): 259-64.

7.Sung RYT, Lam YM, Leung SSF. Blood pressure in Hong Kong Chinese children: correlation with anthropometric data. J HK Coll Cardiol 1994; 2: 99-106.

8.The sixth report of the Joint National Committee on prevention, detection, evaluation and treatment of high blood pressure. Arch Intern Med 1997; 157(21):2413-46.

9.Report on the regional consultation on hypertension prevention and control, Abu Dhabi, United Arab Emirates, 20-22 December 2003. Cairo, Egypt, World Health Organization, Regional Office for the Eastern Mediterranean, 2004 (WHO-EM/ NCD/042/E).

10. Henry CJ, Lightowler HJ, Al-Hourani HM. Physical activity and levels of inactivity in adolescent females ages 11-16 years in the United Arab Emirates. Am J Hum Biol 2004; 16(3):346-53.

11. Ministry of Health, United Arab Emirates Preventive medicine department annual report 2003.

12. Carter AO, Saadi HF, Reed RL, Dunn EV. Assessment of obesity, lifestyle, and reproductive health needs of female citizens of Al Ain, United Arab Emirates. J Health Popul Nutr 2004; 22(1):75-83.

13. Carter $A O$, Elzubeir $M$, Abdulrazzaq $Y M$, Revel $A D$, Townsend A. Health and lifestyle needs assessment of medical students in the United Arab Emirates. Med Teach 2003; 25(5):492-6.

14. Hamadeh RR. Smoking habits of medical students in Bahrain. J Smok Relat Dis 1994; 5:189-95.

15. Hamadeh RR. Smoking in the GCC countries. Bahrain Med Bull 1998; 20:91-94.

16. Bener A, Stwart T, Al-Ketbi LMB. Cigarette smoking habits among high school boys in the United Arab Emirates. Int Q Commun Health Educ 1999; 18:209-22.

17. el Mugamer IT, Ali Zayat AS, Hossain MM, Pugh RN. Diabeties, obesity and hypertension in urban and rural people of bedouin origin in the United Arab Emirates. J Trop Med Hyg 1995; 98(6):407-15.

18. Badrinath P, Al-Shboul QA, Zoubeidi T, Gargoum AS, Ghubash R, El-Rufaie OE. Measuring the health of the nation: United Arab Emirates Health And Lifestyle Survey 2000. Faculty of Medicine \& Health Sciences and College of Economics Al Ain 2002.

19. National High Blood Pressure Education Program. Update on the 1987 Task Force Report on High Blood Pressure in Children and Adolescents: A working group report from the National High Blood Pressure Education 
Program. National High Blood Pressure Education Program Working Group on Hypertension Control in Children and Adolescents. Pediatrics. 1996;98(pt 1):649-58.

20. Percy C, Freedman DS, Gilbert TJ, White L, Ballew C, Mokdad A. Prevalence of hypertension among Navajo Indians: findings from the Navajo and Nutritional survey. J Nutr 1997; 127(10): 2114S-19S.

21. Sugarman JR, White LL, Gilbert TJ. Evidence for a secular change in obesity, height and weight among Navajo Indian school children. Am J Clin Nutr 1990; 52(6): 960-6.

22. Smith C, Riderknecht K. Obesity correlates with increased blood pressure in urban Native American youth. Am J Hum Biol 2003; 15(1): 78-90.

23. Kusuma YS, Babu BV, Naidu JM. Blood pressure levels among cross cultural populations of Visakhapatnam district, Andhra Pradesh, India. Anna Hum Boil 2002; 29(5): 502-12.

24. Schall JI. Sex difference in the response of blood pressure to modernization. AM J Hum Biol 1995; 7: 159-70.

25. Mendelsohn ME, Karas $\mathrm{RH}$. The protective effects of estrogen on the cardiovascular system. N Engl J Med 1999;340(23):1801-11.

26. Brown CD, Higgins M, Donato KA, Rohde FC, Garrison R, Obarzanek $E$ et al. Body mass index and the prevalence of hypertension and dyslipidemia. Obes Res. 2000;8(9):605-19. 27. Gan SK, Loh CY, Seet B. Hypertension in young adults an under-estimated problem. Singapore Med J 2003; 44(9) : 448-52.

28. Sonne-Holm S, Sorensen TI, Jensen G, Schnohr P. Independent effects of weight change and attained body weight on prevalence of arterial hypertension in obese and non- obese men. BMJ 1989; 299(6702):767-70.

29. Thompson D, Edelsberg J, Colditz GA, Bird AP, Oster G. Lifetime health and economic consequences of obesity. Arch Intern Med 1999; 159(18):2177-83.

30. Srinivasan SR, Myers L, Berenson GS. Changes in metabolic syndrome variables since childhood in prehypertensive and hypertensive subjects: the Bogalusa Heart Study. Hypertension. 2006; 48(1): 33-9.

31. Kuschnir MC, Mendonca GA. Risk factors associated with arterial hypertension in adolescents. J Pediatr 2007; 83(4): 335-42.

32. Reich A, Müller G, Gelbrich G, Deutscher K, Godicke R, Kiess W. Obesity and blood pressure-results from the examination of 2365 schoolchildren in Germany. Int J Obes Relat Metab Disord 2003; 27(12):1459-64.

33. Berenson GS, Srinivasan SR, Bao W, Newman WP 3rd, Tracy RE, Wattigney WA. Association between multiple cardiovascular risk factors and atherosclerosis in children and young adults. The Bogalusa Heart study. N Engl Med 1998; 338(23): 1650-6.

34. Davy KP, Hall JE. Obesity and hypertension: two epidemics or one? Am J Physiol Regul Integr Comp Physiol 2004; 286(5): R803-R13.

35. Iannuzzi A, Licenziati MR, Acampora C, Renis M, Agrusta $M$, Romano $L$ et al. Carotid artery stiffness in obese children with the metabolic syndrome. Am J Cardiol 2006;97(4):52831.
36. Schillaci G, Pirro M, Vaudo G, Mannarino MR, Savarese $G$, Pucci $G$ et al. Metabolic syndrome is associated with aortic stiffness in untreated essential hypertension. Hypertension. 2005; 45(6):1078-82.

37. Stelfox HT, Ahmed SB, Ribeiro RA, Gettings EM, Pomerantsev E, Schmidt U. Hemodynamic monitoring in obese patients: the impact of body mass index on cardiac output and stroke volume. Crit Care Med. 2006; 34(4):12436.

38. de Simone G, Devereux RB, Kizer JR, Chinali M, Bella JN, Oberman $A$ et al. Body composition and fat distribution influence systemic hemodynamics in the absence of obesity: the HyperGEN Study. Am J Clin Nutr 2005; 81(4):757-61.

39. Jervase E, Barnabas D, Emeka A, Osondu N. Sex Differences And Relationship Between Blood Pressure And Age Among The Ibos Of Nigeria. The Internet Journal of Biological Anthropology. 2009; 3(2) Available from: URL:http://www.ispub.com/journal/the_internet_journal_o f_biological_anthropology/volume_3_number_2_59/article /sex-differences-and-relationship-between-blood-pressureand-age-among-the-ibos-of-nigeria.html

40. Chirinos JA, Franklin SS, Townsend RR, Raij L. Body mass index and hypertension hemodynamic subtypes in the adult US population. Arch Intern Med. 2009; 169(6):580-6.

41. Gangwisch JE, Heymsfield SB, Boden-Albala B, Buijs RM, Kreier F, Pickering TG et al. Short sleep duration as a risk factor for hypertension: analyses of the first National Health and Nutrition Examination Survey. Hypertension. 2006; 47(5): 833-9.

42. Gottlieb DJ, Redline S, Nieto FJ, Baldwin CM, Newman $A B$, Resnick HE et al. Association of usual sleep duration with hypertension: the Sleep Heart Health Study. Sleep. 2006; 29(8):1009-14. 